\title{
当教室における春䯣腫瘍手術例の検討
}

長崎大学医学部整形外㳆

$\begin{array}{llllll}\text { 中 村 } & & \text { 泰・平 野 } & \text { 徹 } \\ \text { 田 中 宏 } & \text { 和・伊 藤 信 之 } \\ \text { 鈴 } & \text { 木 良 平 } & & & \end{array}$

\section{The Results of Surgical Treatment of Spinal Tumors}

by

\section{Y. Nakamura, T. Hirano N. Ito H. Tanaka and R. Suzuki \\ Department of Orthopaedic Surgery Nagasaki University, School of Medicine}

\begin{abstract}
Nine patients of spinal tumor were treated surgically from 1970 to 1980 . Three cases of them originated in the intramedulla and six cases in the intradura-extramedulla. For all cases, laminectomy and total or partial resection of the tumor was carried out, except in one case (hemangioblastoma-suspect), in which the tumor could not be resected because of a large risk of bleeding. Histological diagnosis was made as follows except for one case:
\end{abstract}

Schwannoma: 6 cases

Ganglioneuroma: 2 cases

The site of tumor was in

cervical spine: 3 cases

thoracic spine: 4 cases

lumbar spine: 2 cases

Postoperative symptoms, such as gait and sensory disturbance, improved in all cases and the histological type and the site of tumor could not explain such good results.

我々の教室では, 1970 年 3 月より, 1980 年 2 月まで の 10 年間に, 9 例の脊髄腫瘍を経験した（表 1 ).

1. 性別 女性 6 名, 男性 3 名

2. 年令 1.5 才 54 才

3. 主訴 手のしびれ感, だるさ. 歩行障害, 腰 痛, 部痛, 仙骨部腫痬等.

4. 症状の初発より手術までの期間

$$
3 \text { 力月〜 } 4 \text { 年 } 10 \text { 力月 }
$$

5. 主な他覚所見

$\begin{array}{ll}\text { 歩行障害 } & 9 \text { 例 } \\ \text { 知覚障害 } & 8 \text { 例 } \\ \text { 膀胱直腸障害 } & 4 \text { 例 }\end{array}$

術前の腰椎穿刺では，全例に蛋白増量を認め，蛋白 量に比例して, キサントクロミーガ出現しているが, case 8 のように出現してない例もある. ミエログラ
表 1

\begin{tabular}{|c|c|c|c|c|c|c|}
\hline case & sex & age & c. C. & duration & sensory & gait \\
\hline 1 & $\mathrm{~m}$ & 40 & $\begin{array}{l}\text { pain in } \\
\text { buttock }\end{array}$ & $3.5 \mathrm{M}$ & & impossible \\
\hline 2 & $m$ & 54 & \begin{tabular}{|c|} 
dulliness \\
in hands
\end{tabular} & $3 Y 2 M$ & & spastic \\
\hline 3 & $f$ & 8 & limping & $3 M$ & & impossible \\
\hline 4 & $f$ & 1.5 & $\begin{array}{l}\text { sacral } \\
\text { tumor }\end{array}$ & $4 M$ & & paralytic \\
\hline 5 & $f$ & 51 & lumbago & $6 \mathrm{M}$ & & impossible \\
\hline 6 & $m$ & 37 & $\begin{array}{l}\text { dullness } \\
\text { in hand }\end{array}$ & $4 Y 10 M$ & & impossible \\
\hline 7 & $f$ & 54 & \begin{tabular}{|c|} 
gait \\
disturbance
\end{tabular} & $11 \mathrm{M}$ & & spastic \\
\hline 8 & $f$ & 25 & $\begin{array}{l}\text { numbness } \\
\text { in hands }\end{array}$ & $4 Y$ & & spastic \\
\hline 9 & $f$ & 40 & lumbago & $4 M$ & & impossible \\
\hline
\end{tabular}


ムでは，頸椎部 3 例，胸椎部 4 例，腰仙椎部 2 例に閉 塞像がみられ，完全閉塞例 6 例，不完全閉塞像 3 例で あった. これらの症例に対し，椎弓切除術と腫瘍の摘 出を行なった. case 8 では，大出血を考えて，椎弓 切除術のみを行なった.

術後の組織診では, schwannoma 6例, ganglioneuroma 2 例であり, case 8 は, 血管造影, 並び に術中所晃より hemangioblastoma が最も考えら れた.とれらのうち ganglioneuroma の 2 例が硬膜 外，他は硬膜内髄外腫瘍であった（表 2).

\section{表 2}

\begin{tabular}{|c|c|c|c|c|c|}
\hline \multirow{2}{*}{ case } & \multirow{2}{*}{\multicolumn{2}{|c|}{\begin{tabular}{|c|c|}
\multicolumn{2}{|c}{ C. S.F. } \\
Proten & Xanthochromia \\
\end{tabular}}} & \multicolumn{2}{|c|}{ myelogram } & \multirow{3}{*}{$\begin{array}{c}\text { diagnosis } \\
\text { schwannoma }\end{array}$} \\
\hline & & & Site & 810 ck & \\
\hline $1_{40 y \mathrm{M}}$ & 164 & - & L. 4 5 & comp. & \\
\hline $2_{\text {SLYM }}$ & 100 & - & C. $2 \sim 3$ & incomp. & schwannoma \\
\hline $3_{8 y . F}$ & 360 & - & Th. $3-5$ & comp. & ganglioneuroma \\
\hline $4_{15 . \mathrm{F}}$ & 680 & + & below L.4 & incomp. & ganglione uroma \\
\hline $5_{5 l y F}$ & 590 & + & Th.9-10 & comp. & schwannoma \\
\hline $6_{3 y, M}$ & 600 & + & C. $5 \sim 7$ & comp. & schwannoma \\
\hline $7_{54 y, F}$ & 1000 & + & Th.9 10 & comp. & schwannoma \\
\hline $8_{25 y F}$ & 738 & - & C. $1-3$ & incomp. & $\begin{array}{c}\text { hemangio- } \\
\text { blastoma susp. }\end{array}$ \\
\hline $9_{40, \mathrm{~F} F}$ & 2400 & + & Th.4 5 & comp. & schwannoma \\
\hline
\end{tabular}

hepatoma で死亡した case 2 を除き， 5 力月か ら 8 年 6 力月の follow-up の結果では，知覚障害に 関しては, case 4, case 9 で, 左足部に軽度の知覚

表 3

\begin{tabular}{|c|c|c|c|c|c|c|c|}
\hline case & sex & age & before & surgery & follow up & after & surgery \\
\hline & & & & Ga: & & $\frac{\operatorname{sen} s x}{2}$ & Gat \\
\hline 1 & $m$ & 40 & & impossible & $8 Y 6 \mathrm{M}$ & & normal \\
\hline 2 & $m$ & 54 & & spastic & died & & (possible) \\
\hline 3 & $f$ & 8 & & impossible & $7 Y 3 M$ & & spastic \\
\hline 4 & $f$ & 1.5 & & limping & $6 Y 6 \mathrm{M}$ & & paralytic \\
\hline 5 & $f$ & 51 & & impossible & $4 Y 10 M$ & & spastic \\
\hline 6 & $m$ & 37 & & impossible & $2 Y$ & $y_{i}$ & normal \\
\hline 7 & $f$ & 54 & & spastic & $1 Y 11 \mathrm{M}$ & & normal \\
\hline 8 & $f$ & 25 & & spastic & $11 \mathrm{M}$ & is & normal \\
\hline 9 & $f$ & 40 & & impossible & $5 \mathrm{M}$ & & spastic \\
\hline
\end{tabular}

低下を残すのみで，他は完全回復，歩行に関しても， 不能であった者 5 名は，いずれも歩行不能となり，内 4 名が, 㾏性歩行を行なっていた. 2 名は正常歩行之 なり， case 4 は，麻瘀性歩行を呈していた。 また， case $4 ， 5 ， 6 ， 9$ の 例にみられた膀胱直腸障害も回 復している(表 3 )。

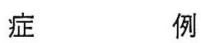

1. case 4.1 .5 才女子

跛行と仙骨部腫瘍を主訴として来院，排尿障害，右 下肢の知覚低下，右アキレス腱反射の低下を認め，単
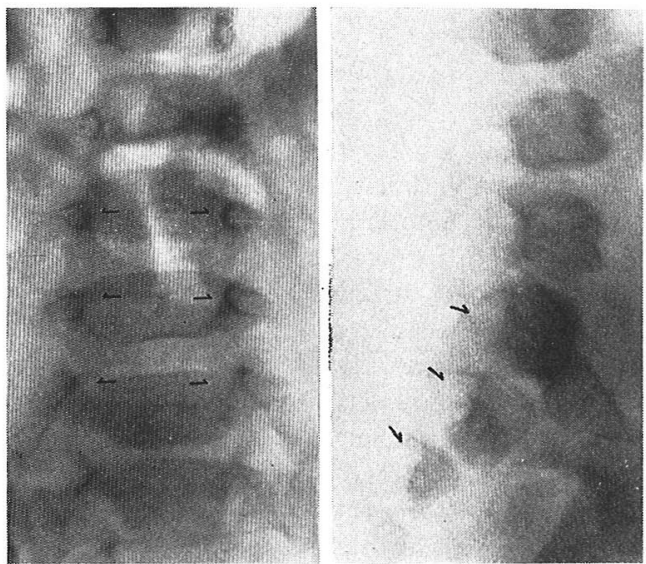

Case 4

Famale 1.5 yrs.

図 1
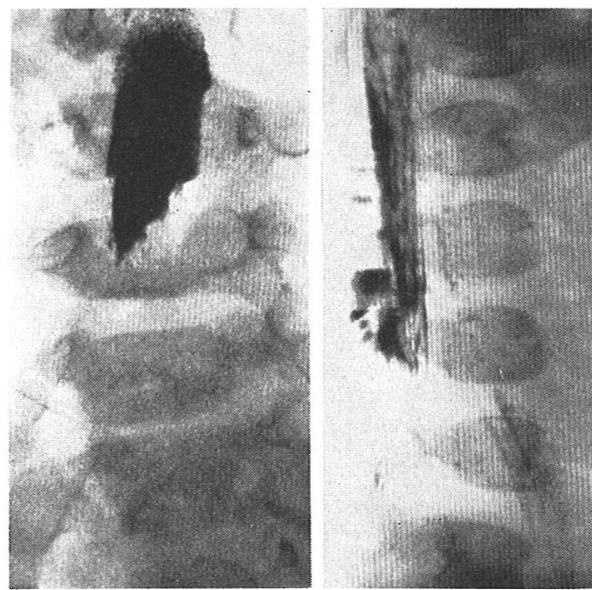

Case 4

Famale 1.5 yrs.

図 2 
純 $\mathrm{X}$ 線像で $\mathrm{L}_{4}-\mathrm{L}_{5}$ の椎体の前後径の狭少化之, 椎 弓椎間の拡大を認めた（図1）。春䯣造影では，同部 に一致して造影剤の停止を認めた。手術は椎弓切除術 と仙骨部より第 3 腰椎にかけての腫瘍の摘出を行なっ たが，腫湯の一部は脊㵦をとり巻いており，痹着が強 く，全摘不可能であった。組織診では, malignant ganglioneuroma であり, さらに外科的検索により, 後腹膜腫演を摘出した後, 放射線療法を行なった（図 $2)$.

術後 6 年 9 力月後の現在, 再発徴候もなく, 前脛骨 筋, 腓腹筋を中心とした下腿筋群の完全麻疩と, 右足 の知覚低下があり，跛行している．単純 X線正面像で は, 椎弓根がやや拡大しているが, 側面像での前後径 は, 正常化している（図3).
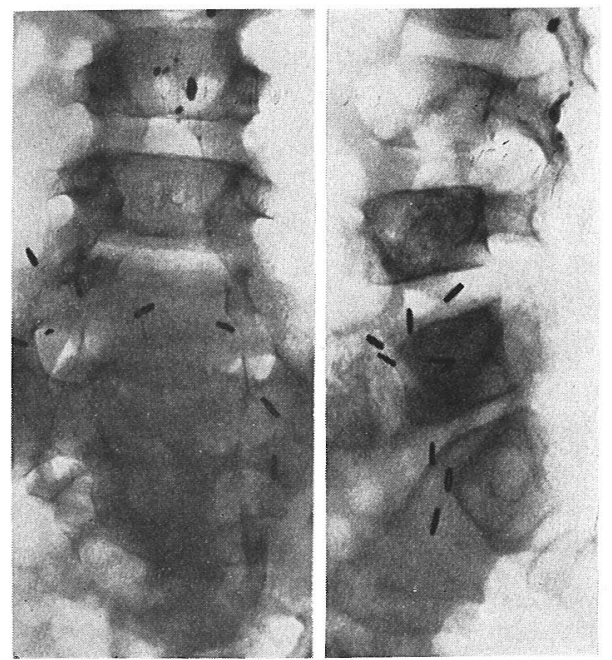

Case 4

Famale 1.5 yrs, after surg.

図 3

\section{Case 637 才男性}

両手のしびれ感, 左肩の疼痛を主訴として来院し た. 脊䯇造影で，第 5 〜第 7 頙椎にかけての完全閉塞 像を呈した。入院時は, 両上肢の知覚低下が主症状で あったが, 入院後, 歩行不能, 膀胱直腸障害, $L^{7} レ$ ベル以下の知覚低下が出現して来た為, 早急に椎弓切 除と腫㻤摘出走行なった。組織診では, Antoni A 型 $5 \%$ ，B 型 $95 \%$ の割合加ら成る schwannoma であった. 術直後より, 知覚, 運動の著しい改善がみ られ，4 週目で SOMI 装具装着, 運動訓練を開始, 術後 2 年経過した現在, 知覚障害, 膀胱直腸障害な

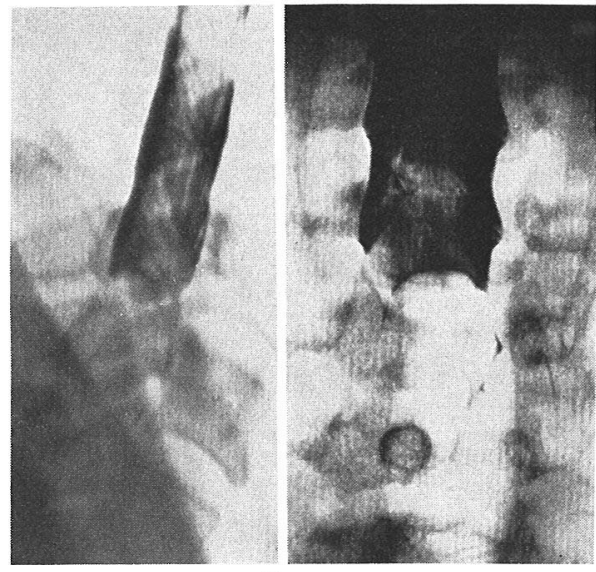

Case 6

Male 37 yrs.

図 4

た. 術後 10 力月後の現在は，右手挙上 $70^{\circ}$ ，書字可 能，上下肢に痙性があり，今後症状が進行するようで く，歩行は正常である(図 4).

3. Case 825 才性

雨上肢のしびれ感, 右手の挙上制限, 䉆手変形で来 院した。術前の知覚障害は $L_{4}$ レベル以下で，書字不 能, 痙性歩行を呈していた。単純 $\mathrm{X}$ 線正面像では, 特 に異常を認めないが，側面像で，脊柱管の拡大像がみ られ（図 5)，術前，血管造影では，春柱管加ら，頭 蓋内に拡がる, hyper-vascular な腫瘍を認めた. 手 術は大孔拡大術, 及び, $\mathrm{C}_{1} \sim \mathrm{C}_{4}$ の椎弓切除術を行な い, 硬膜内に，赤色スポンジ様組織を認めたが，出血 が多く, 生検屯出来ずに, 手術を中止した. 術前, 術 中の所見より, hemangioblastoma が最も考えられ

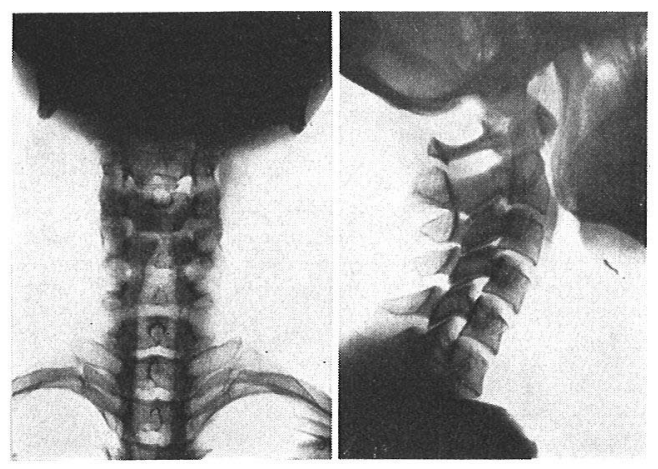

Case 8

Famale 25 yrs.

図 5 


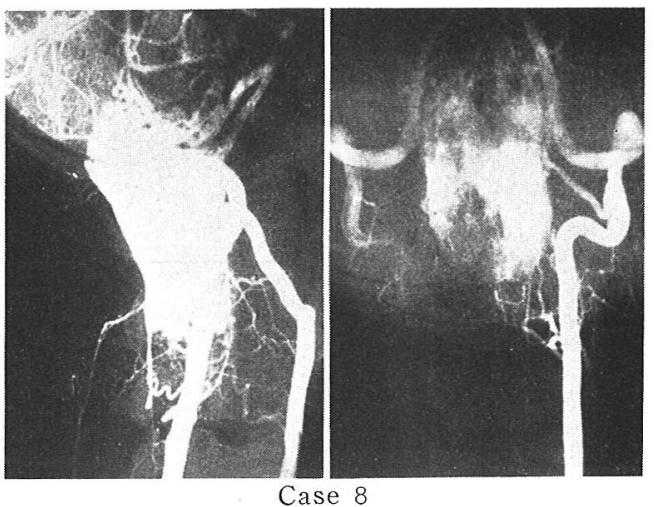

Famale 25 yrs.

図 6

あれば，放射線療法，embolization 等を考えている (図6).

\section{ま と め}

過去 10 年間に 経験した 9 例について述べたが，腫 瘍発生部位は, 胸椎部に最も多く, 次いで, 頸椎部, 腰仙椎部であり, 硬膜外の ganglioneuroma 2 例, また, hemangioblastoma を思わせた 1 例を除き, 他は全て硬膜内䯣外腫瘍であった。組織型では, schwannoma が最も多かったが, meningioma の例は 認めなかった。発生頻度の少ない ganglioneuroma を2例認めた，完全摘出出来たいずれの症例でも，知 覚, 歩行の改善は, 腫瘍発生の高位, 症状の初発より 手術までの期間，あるいは，follow-up の期間とは関 係なく，閉塞の程度と屯関係しなかった．歩行に関し ては，痙性歩行が比較的長く続くようである。良好な

表 4

\begin{tabular}{|c|c|c|c|c|c|c|c|}
\hline \multirow{2}{*}{ Case } & \multirow{2}{*}{$\begin{array}{l}\text { Before } \\
\text { Duration }\end{array}$} & \multicolumn{2}{|c|}{ Surgery } & \multirow{2}{*}{ Diagnosis } & \multicolumn{3}{|c|}{ After Surgery } \\
\hline & & Sensory & Gait & & Follow-up & Sereory & Gatt \\
\hline $140, \mathrm{M}$ & $3.5 \mathrm{M}$ & Eil & impossible & Schwannoma & $8 \mathrm{r} 6 \mathrm{M}$ & US & normal \\
\hline 2 s4yM & $3 \times 2 \mathrm{M}$ & & spastic & Schwannoma & died & $u$ & (possible) \\
\hline $38 y F$ & $3 \mathrm{M}$ & & impossible & Ganglioneuroma & $7 \times 3 \mathrm{M}$ & bij & spastic \\
\hline $4: 5 y F$ & $4 \mathrm{M}$ & in & paralytic & Ganglioneuroma & $6 \times 6 \mathrm{M}$ & ij & paralytic. \\
\hline 5 51 yF & $6 \mathrm{~m}$ & & impossible & Schwannoma & $4 \times 10 \mathrm{M}$ & Qij & spastic \\
\hline $6_{3 y_{Y M}}$ & $4 Y 10 M$ & & impossible & Schwannoma & $2 y$ & 8 & normal \\
\hline $754 y^{F}$ & $11 \mathrm{M}$ & 8 & spastic & Schwannoma & 1 Y $11 \mathrm{M}$ & 8 & normal \\
\hline $825 \mathrm{yF}$ & $4 \mathrm{y}$ & & spastic & \begin{tabular}{|c|} 
Hemangio- \\
blastoma susp
\end{tabular} & $11 \mathrm{M}$ & is & normal \\
\hline $940 \mathrm{yF}$ & $4 \mathrm{M}$ & , & impossible & Schwannoma & $5 M$ & is & spastic \\
\hline
\end{tabular}

結果が得られたのは, schwannoma が多かった事, あるいは，硬膜内髄外腫浣が多かった為と推察される （表 4 ）。

文献

1) 佐藤 修 - 他：春䯣硬膜外䯣膜腄。脳神経外 科, 1(6): 513-518, 1973 .

2) 干方崎裕夫：脊䯣䯣内腫濠の乎術。脳神経外 科, 2(7.8): 521-527, 1974.

3）鈴木良平・他：脊䯣硬膜外露腫の 2 例。日整会 誌，45：1043-1049，1971.

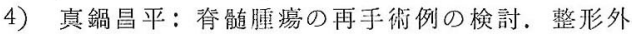
科, 29.1 : 11-17, 1978 .

5) 白石英典 - 他: 若年者の脊䯣腫崵. 整形外科, 26. 7: 637-643, 1975.

6）初山泰弘 - 他：頸咀腫湯の症状と予後. 整形外 科, 20. 10: 1043-1053, 1969.

7) Orthopaedic aspects of intraspinal tumors in infants and children. Mihran $\mathrm{O}$. Tachdjian, et al. : J. B. J. S. Vol. 47-A, No. 2, 223-248, 1965.

\section{質 問鳥取大学整形川上 俊文}

脊䯣血管腫の分類方法は, 組織学的に行なうか. 血 管造影所見でおこなうかまようところでありますが, 先生は Angiogram の所見で Haemoangioblastoma と診断されております. 分類方法について御意見 をお聞せ下さい.

\section{回 答}

長崎大整形 平野徹

hemangioblastoma を推察した根拠・組織学的検 索はなされていないが, Kngiography，肉眼的にも， 血管性の腫瘍と思われ, しかも原生部位は infratentorial で境界は比較的明瞭であった。

以上の事から hemangioblastoma が最も考えら れる。

\section{質 問} 山口大学 河合 伸也

奉䯣腫瘍は一般に全摘が可能であれば予後が良いと されているのですが，しかし実際には疥㾕が残存する もの屯少なくなく, 先生の症例 39 例中 4 例が normal にまで回復しているようですが，術前に例えば 発症から手術までの期間, 圧迫の程度など諸々の要素 のうちでどれがもっとも予後と関係深いでしょうか.

\section{回 答 長崎大学医学部整形外科 伊藤 信二}

Case 1 の症例の ope 所見は現在はっきりした事 をおぼえてないので，よく，理由が分りません. 